\title{
WHO cone bio-assays of classical and new-generation long-lasting insecticidal nets call for innovative insecticides targeting the knock-down resistance mechanism in Benin
}

\author{
Marius Allossogbe ${ }^{1,2^{*}}$, Virgile Gnanguenon ${ }^{1,2}$, Boulais Yovogann ${ }^{1,2}$, Bruno Akinro ${ }^{1}$, Rodrigue Anagonou ${ }^{1,2}$, \\ Fiacre Agossa ${ }^{1,2}$, André Houtoukpe ${ }^{3}$, Germain Gil Padonou ${ }^{1,2}$ and Martin Akogbeto ${ }^{1,2}$
}

\begin{abstract}
Background: To increase the effectiveness of insecticide-treated nets (ITN) in areas of high resistance, new longlasting insecticidal nets (LLINs) called new-generation nets have been developed. These nets are treated with the piperonyl butoxide (PBO) synergist which inhibit the action of detoxification enzymes. The effectiveness of the new-generation nets has been proven in some studies, but their specific effect on mosquitoes carrying detoxification enzymes and those carrying both detoxification enzymes and the knock-down resistance gene in Benin is not well known. Thus, the objective of this study is to evaluate the efficacy of LLINs treated with PBO on multi-resistant Anopheles gambiae s.l.
\end{abstract}

Methods: The study occurred in seven cities in Benin, Abomey, Cotonou, Porto-Novo, Zangnanado, Parakou, Malanville and Tanguiéta, and included ten locations selected on a north-south transect. Mosquito larvae were collected from these sites, and adult females from these larvae were exposed to single-pyrethroid-treated nets (LifeNet, PermaNet 2.0, Olyset Net) and bi-treated nets (PermaNet 3.0 and Olyset Plus) based on their level of resistance and using WHO cone tests following WHO guidelines.

Results: The different LLINs showed 100\% mortality of the susceptible laboratory strain Kisumu and the resistant strain Ace-1R Kisumu. However, with the resistant laboratory strain kdr-Kisumu, mortality was low (16-32\%) for all LLINs except PermaNet 3.0 (82.9\%). The mortality of local strains carrying only the $k d r$ mechanism varied from 0 to $47 \%$ for the single-pyrethroid-treated LLINs and 9 to $86 \%$ for bi-treated LLINs. With local strains carrying several mechanisms of resistance ( $k d r+$ detoxification enzymes), the observed mortality with different LLINs was also low except for PermaNet 3.0, which induced significantly higher mortality, usually greater than $75 \%(p<0.001)$, with multiresistant strains. The inhibition of the mortalities induced by the LLINs (11-96\%) on multi-resistant field populations was similar to the inhibition observed with the laboratory strain carrying only the knock-down resistance mechanism (kdr-Kisumu) ( $p>0.05)$.

Conclusion: This study showed that the new-generation LLINs treated with pyrethroids and PBO showed better efficacy compared to conventional LLINs. Although the addition of PBO significantly increased the mortality of mosquitoes, the significant role of the $k d r$ resistance gene in the low efficacy of LLINs calls for LLIN technology innovation that specifically targets this mechanism.

Keywords: LLINs, Bio-efficacy, Piperonyl butoxide, Resistant mosquitoes

\footnotetext{
*Correspondence: palutec@yahoo.fr

${ }^{1}$ Centre de Recherche Entomologique de Cotonou (CREC), Cotonou, Benin

Full list of author information is available at the end of the article
} 


\section{Background}

Malaria is a major public health problem worldwide, and particularly so in Benin. It remains a permanent threat from its high morbidity ( 214 million) and mortality $(438,000)$. Africa is the most endemic region affected $(395,000$ deaths per year) [1]. It affects onefifth of the world population. However, this proportion has decreased significantly by $37 \%$ between 2000 and 2015 due to the effect of malaria prevention and treatment methods, including long-lasting insecticidal nets (LLINs), indoor residual spraying of residual insecticides (IRS), chemo-prevention for pregnant women and children, and therapeutic treatment with artemisinin-based combinations.

Among these prevention methods, LLINs have emerged in recent years as a privileged tool to prevent malaria. The insecticides selected by the World Health Organization (WHO) for LLIN treatment are pyrethroids, which have little toxicity to humans, are effective at low doses, are fast acting (knock-down effect) and, along with repellants, have an irritant effect [2]. The Abuja Conference, which brought together all the leaders of Africa and other UN representative states, donors and NGOs in April 2000, gave impetus to a political commitment to the fight against malaria with the use of insecticide treated nets (ITNs) [3]. Efforts are being made to increase accessibility for populations, especially pregnant women and children under five, who are vulnerable to malaria, a major cause of perinatal mortality, low birth weight and maternal anaemia [1].

Several research studies have been conducted and have shown the effectiveness of ITNs in the fight against malaria in Burkina Faso [4], Cameroon [5], Gambia [69], the Democratic Republic of Congo [10], Kenya [11], Ghana [12], Benin [13] and Côte d'Ivoire [14].

However, several studies have shown that Anopheles gambiae s.l. has developed strong resistance to pyrethroids and DDT in Benin, with a very high knock-down resistance frequency of approximately $80 \%$ in the urban areas of Cotonou and in rural areas [15-23].

Despite this resistance developed by An. gambiae s.l. to pyrethroids, LLINs remain effective in vector resistance areas [24] and provide protection through their mechanical barrier role [25]. However, Asidi et al. [26] showed a decrease in their effectiveness in areas of high resistance of Anopheles in southern Benin. Major developed resistance mechanisms are the targets of modification $(k d r$ resistance and ace-1R) and metabolic resistance (overexpression of detoxification enzymes, oxidases, esterases, GST) [27]. The $k d r$ mutation is associated with pyrethroid and DDT resistance, and ace-1R is associated with organophosphate and carbamate resistance (two classes of insecticides which are not used to treat LLINs) $[15,28]$.
To increase the effectiveness of ITNs in areas of high resistance, new nets treated with a so-called new-generation of chemicals has been developed. They are treated with a synergist called piperonyl butoxide (PBO). For some LLINs, the PBO is used on all sides of the net $\left(\right.$ Olyset Plus $\left.^{\circledR}\right)$. For others, only the upper part of the net is processed (PermaNet ${ }^{\circledR} 3.0$ ). The principle of an ITN synergist is to inhibit the action of detoxification enzymes, which will result in increasing the effectiveness of the insecticide against resistant populations of mosquitoes.

Evidence of the efficacy of PermaNet 3.0 has been shown in some studies, particularly in Tanzania [29], but we do not know its specific action on mosquitoes carrying detoxification enzymes and on those carrying both detoxification and $k d r$ mechanisms in West Africa, particularly in Benin. There have been limited data on the bio-efficacy of new-generation LLINs against multiresistant mosquitoes in Africa in general and particularly in Benin. Thus, the objective of this study is to evaluate the efficacy of long-lasting insecticidal nets (LLINs) treated with $\mathrm{PBO}$ on multi-resistant An. gambiae s.l. populations in Benin. It aims to assess the bio-efficacy of LLINs in areas with a high frequency of molecular resistance genes ( $k d r$ and $a c e-1 R)$ and over-expression of detoxification enzymes (oxidases, esterases, GST). The efficacy of the new-generation LLINs against pyrethroidresistant Anopheles was also compared to that of conventional LLINs.

\section{Methods}

\section{Study design}

This study is transversal and compares variability of the efficacy of two different types of LLINs against An. gambiae s.l. carrying $k d r$ resistance mutations and detoxification enzymes in Benin. The two types of LLINs included conventional LLINs only treated with pyrethroids (Olyset Net, LifeNet, and PermaNet 2.0) and a second type of new-generation LLIN treated with pyrethroids and piperonyl butoxide (PBO), which inhibits the action of enzymes, particularly oxidases.

The study was conducted in Benin, a West African country from June 2015 to March 2016. Among the 12 departments of Benin surveyed, seven were selected in this study (Atlantique, Littoral, Oueme, Zou, Borgou, Atacora and Alibori). Priority was given to areas where higher oxidase activity was observed compared to the susceptible strain An. gambiae Kisumu. They were represented by Abomey, Cotonou, Porto-Novo, Zangnanado, Parakou, Malanville and Tanguiéta districts. The assessment of oxidase activity was conducted on $50 \mathrm{An}$. gambiae s.l. collected from each district using haem-peroxidase assay as described by Brogdon et al. [30]. 
The larvae of these mosquito populations were collected in different ecological areas (vegetable, urban, rice and cotton areas). The study was also conducted on resistant laboratory strains (kdr-Kisumu and ace-1R-Kisumu).

\section{Study sites \\ Malanville}

Malanville district is bordered on the north by the Republic of Niger, on the south by Kandi and Segbana districts, on the west by Karimama district and on the east by the Republic of Nigeria. It has an area of $3016 \mathrm{~km}^{2}$ and had a population of 144,843 inhabitants in 2013 (Fig. 1).

\section{Tanguieta}

It is bordered on the north by the Republic of Burkina Faso, on the south by Boukoumbe district, on the east by Kerou, Kouande and Tounkountouna districts and on the west by Materi and Cobly districts. It covers an area of $5456 \mathrm{~km}^{2}$ and had a population of 77,987 inhabitants in 2013 (Fig. 1).

\section{Abomey-Calavi}

Abomey-Calavi is bounded on the north by Ze district, on the south by the Atlantic Ocean, on the east by Cotonou and So-Ava districts, and on the west Ouidah and Tori-Bossito districts. It has an area of $539 \mathrm{~km}^{2}$ and had a population of 438,564 inhabitants in 2013 (Fig. 1).

\section{Cotonou}

Cotonou is bordered on the North by So-Ava district and Nokoue lake, on the south by the Atlantic Ocean, on the east by Seme-Podji and on the west by Abomey-Calavi district. It has an area of $79 \mathrm{~km}^{2}$ and had a population of 947,917 inhabitants in 2013 (Fig. 1).

\section{Porto-Novo}

Porto-Novo is bounded on the north by Akpro-Missérete and Avrankou districts, on the south by Seme-Podji, on the west by Aguegues district and on the east by Adjarra district. It covers an area of $223,552 \mathrm{~km}^{2}$ and had a population of 318,608 inhabitants in 2013 (Fig. 1).

\section{Parakou}

It is bordered on the north by N'Dali district and on the south, east and west by Tchaourou district; it has an area of $441 \mathrm{~km}^{2}$ and had a population of 213,498 inhabitants in 2013 (Fig. 1).

\section{Zangnanado}

This town is bounded on the north by Dassa-Zoume district, on the south by Ouinhi and Zogbodomey districts, on the west by Cove, Zakpota and Djidja districts and on the east by Ketou and Adja-Ouere. It has an area of
$540 \mathrm{~km}^{2}$ and had a population of 52,387 inhabitants in 2013 (Fig. 1).

\section{Larvae collection}

Bio-efficacy tests were conducted at various selected sites. Such tests required mosquitoes of 2-5 days old, so the larvae were collected. These collections were conducted in the different localities mentioned above. Anopheles gambiae s.l. larvae and pupae were collected from different locations at each site and carried to the insectarium of the Entomological Research Center of Cotonou (CREC), where they were reared to adult stage at a relative humidity of $70-80 \%$ and a temperature of $25-30{ }^{\circ} \mathrm{C}$. Female adults aged $2-5$ days were used for bioefficacy tests.

\section{Highlighting resistance mechanisms}

Before the bioassays, living and dead mosquito populations kept after susceptibility testing were analyzed by PCR to detect the genotypes of the $k d r$ gene. The detection of $k d r$ mutation L1014F was performed according to the method of Martinez-Torres et al. [31].

For the molecular characterization of insecticide resistance, two molecular markers were used for characterization of the resistance genes, $k d r$ and $a c e-1 R$.

Similarly, for the biochemical characterization of resistance mechanisms, biochemical assays were performed to compare the activity levels of mixed function oxidases (MFO), non-specific esterases (NSE) and glutathione S-transferases (GST) according to the protocol described by Hemingway et al. [32] in susceptible Kisumu and field An. gambiae strains. The mosquitoes used for biochemical analysis had not been exposed to insecticides before the biochemical assessment. These enzyme activities were measured using a sample of 50 mosquitoes per site.

\section{Mosquito nets}

Five types of long-lasting insecticidal nets were evaluated in this study. The group of mono-treated LLINs included LifeNet (polypropylene LLIN with fiber coated with $340 \mathrm{mg} / \mathrm{m}^{2} \pm 25 \%$ deltamethrin), Olyset Net (polyethylene LLIN with permethrin incorporated into the fibers at $20 \pm 3 \mathrm{~g} / \mathrm{kg}$ ), and PermaNet 2.0 (polyester LLIN with fiber coated with deltamethrin at $55 \mathrm{mg} / \mathrm{m}^{2} \pm 25 \%$ ). The group of new-generation LLINs included: Olyset Plus (same characteristics as Olyset Net but with PBO incorporated throughout the LLIN) and PermaNet 3.0 (polyethylene roof with deltamethrin at $2.8 \mathrm{~g} / \mathrm{kg} \pm 25 \%$ and $\mathrm{PBO}$ at $4.0 \mathrm{~g} / \mathrm{kg} \pm 25 \%$ incorporated into the fibers, and polyester lateral sides with the fibers coated with deltamethrin at $2.8 \mathrm{~g} / \mathrm{kg} \pm 25 \%)$. All these nets were obtained from local markets. All nets included in the study are rectangular and were selected by type. 


\section{Cone test}

The cone test is used to assess the effectiveness of an insecticide and its persistence on the net. It was conducted following the WHO protocol. This test aims to compare the behaviour of mosquitoes while in contact with treated mosquito nets without $\mathrm{PBO}$ or with $\mathrm{PBO}$.

Cone tests were performed on five types of nets (Olyset Plus, Olyset Net, LifeNet, PermaNet 2.0 and PermaNet 3.0). These tests were carried out using fragments of LLINs $(30 \mathrm{~cm} \times 30 \mathrm{~cm})$ cut from five $(05)$ positions on each net. Two standard cones were fixed with a plastic sheet on each of the five (05) screen fragments. For PermaNet 3.0 LLIN, an additional two cones were added on the PBO-containing roof. Five unfed An. gambiae females aged 2-5 days (Kisumu or wild type) were introduced into each cone placed on the LLIN for $3 \mathrm{~min}$. After exposure, the mosquitoes were removed from the cones using a mouth aspirator and then transferred into paper cups and provided $10 \%$ sugar solution. Mosquito knock-down was recorded every $5 \mathrm{~min}$ for $60 \mathrm{~min}$. A negative control (untreated net) was included in each series of cone tests. After $24 \mathrm{~h}$ of observation, mortality post exposure was recorded. No correction of mortality with Abbott's formula was used as mortality in the control was $<5 \%$. All these operations were carried out at a temperature of $25 \pm 2{ }^{\circ} \mathrm{C}$ and a humidity of $70 \pm 10 \%$.

\section{Data analysis}

According to the WHO, the bio-effectiveness threshold is 95\% knock-down and 80\% mortality for laboratory mosquitoes; but for resistant field mosquito populations, we used a threshold of $70 \%$ knock-down and 50\% mortality. Therefore, all nets showing less than 95\% knockdown for laboratory mosquitoes and $70 \%$ for field mosquitoes after $60 \mathrm{~min}$, or less than $50 \%$ mortality for laboratory mosquitoes and $50 \%$ for field mosquitoes after $24 \mathrm{~h}$ of observation, were considered ineffective. These knockdown thresholds were chosen taking into account the $k d r$ resistance level observed in the country in general (>50\%).

The inhibition of mortality induced by resistance mechanisms was estimated using the following equation:

$$
\text { Inhibition }=1-(\mathrm{p} 1 / \mathrm{p} 2) \times 100
$$

where $\mathrm{p} 1=$ proportion of resistant mosquitoes dead and p2 = proportion of susceptible Kisumu mosquitoes dead.

To determine if there was any significance difference between the outcome variables (knock-down, mortality and inhibition), Poisson regression (for numeric data) and logistic regression (for proportional data) were used. The 50 and 95\% knock-down times and their confidence intervals were obtained after log-probit regression using the method described by Finney [33].

\section{Results}

Characteristics of the studied mosquito populations

The majority of female mosquitoes were collected and identified morphologically as An. gambiae s.l. The biochemical and molecular analyses indicated that among ten sites, five showed significantly higher oxidase activity than the susceptible strain Kisumu (Table 1). Esterases were significantly expressed in the Tanguieta mosquito population (Table 1). Over-expression of glutathioneS-transferase was observed at four sites (Table 1). However, the allelic frequency of the $k d r$ mutation was high at almost all sites and ranged from 0.03 to 0.93 .

\section{Knock-down (KD) and mortality of laboratory strains}

Figure 2 shows the proportion of laboratory mosquitoes (ace-1R-Kisumu, kdr-Kisumu, and susceptible Kisumu) knocked down after $60 \mathrm{~min}$ for each LLIN. The Olyset Plus and PermaNet 3.0 LLINs induced 100\% knock-down of An. gambiae Kisumu. The knock-down effect was 96.15\% for Olyset, $90.2 \%$ for LifeNet and 93.22\% for PermaNet 2.0.

With the ace-1R-Kisumu strain, which carries the acetylcholinesterase-1 resistance gene, there was a knockdown effect greater than $95 \%$ for all nets, with $98.11 \%$ for LifeNet, 100\% for Olyset, 98.18\% for Olyset Plus, 97.96\% for PermaNet 2.0, and 98.78\% for PermaNet 3.0 (Fig. 2).

For the kdr-Kisumu strain (carrying the resistance knock-down), the knock-down effects observed were 89.29\% for LifeNet, 63.64 for Olyset Net, $71.43 \%$ for Olyset Plus, 45.78 for PermaNet 2.0 and $71.05 \%$ for PermaNet 3.0 (Fig. 2).

Kisumu and ace-1R-Kisumu (Fig. 3). With the kdrKisumu strain, mortality was $16 \%$ for Olyset Net, $26 \%$ for PermaNet 2.0, 28\% for LifeNet, and 32.1\% for Olyset Plus but was more than $82.9 \%$ for PermaNet 3.0. Therefore, based on the bio-efficacy threshold set by WHO (80\%), PermaNet 3.0 was effective on all laboratory strains, and Olyset Plus was only effective on the susceptible and aceR1-Kisumu strains (Fig. 3).

Inhibition of mortality conferred by the $k d r$ resistance gene Comparing the mortality observed with the susceptible Kisumu strain with that of the resistant kdr-Kisumu strain, the inhibition of mortality induced by the $k d r$ gene regarding the effectiveness of LLINs was $84 \%$ for Olyset Net, $74 \%$ for PermaNet $2.0,72 \%$ for LifeNet, $68 \%$ for Olyset Plus and 17\% for PermaNet 3.0.

\section{Knock-down (Kd) effect and mortality induced by mosquito nets on local An. gambiae s.l.}

Approximately 2819 local An. gambiae s.l. mosquitoes and 889 An. gambiae Kisumu laboratory strain mosquitoes were tested on different types of LLINs. Tables 2 and 


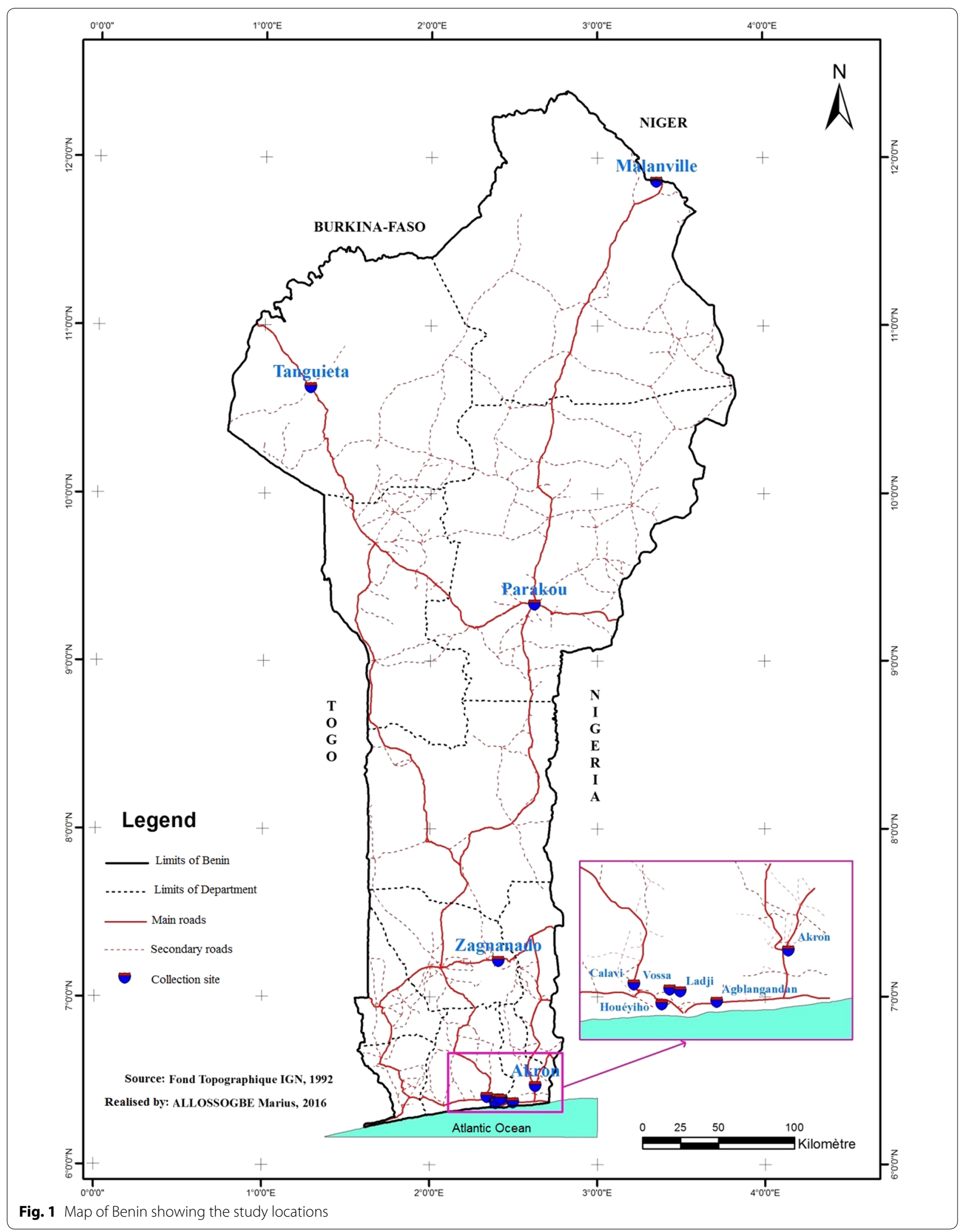


Table 1 Biochemical and molecular characteristics of the Anopheles gambiae s.l. populations tested

\begin{tabular}{llllll}
\hline $\begin{array}{l}\text { Strains of An. gambiae } \\
\text { s.l. }\end{array}$ & $\begin{array}{l}\text { Average oxidase activ- } \\
\text { ity (min/mg protein) }\end{array}$ & $\begin{array}{l}\text { Average a esterase } \\
\text { activity (min/mg } \\
\text { protein) }\end{array}$ & $\begin{array}{l}\text { Average } \beta \text { esterase } \\
\text { activity (min/mg } \\
\text { protein) }\end{array}$ & $\begin{array}{l}\text { Average glutathione- } \\
\text { S-transferase activity } \\
\text { (min/mg protein) }\end{array}$ & $\begin{array}{l}\text { kdr frequency } \\
\text { pring }\end{array}$ \\
\hline Kisumu & $0.1015^{\mathrm{a}}$ & $0.07409^{\mathrm{a}}$ & $0.07655^{\mathrm{a}}$ & $0.3846^{\mathrm{a}}$ & $0.79^{\mathrm{b}}$ \\
Agblangandan & $0.07966^{\mathrm{a}}$ & $0.07883^{\mathrm{a}}$ & $0.06117^{\mathrm{a}}$ & $0.739^{\mathrm{a}}$ & $0.03^{\mathrm{a}}$ \\
Abomey-Calavi & $0.08454^{\mathrm{a}}$ & $0.07149^{\mathrm{a}}$ & $0.05929^{\mathrm{a}}$ & $0.4295^{\mathrm{a}}$ & $0.93^{\mathrm{b}}$ \\
Akron & $0.1604^{\mathrm{b}}$ & $0.08589^{\mathrm{a}}$ & $0.07897^{\mathrm{a}}$ & $2.221^{\mathrm{b}}$ & $0.74^{\mathrm{b}}$ \\
Houeyiho & $0.17 .39^{\mathrm{b}}$ & $0.07694^{\mathrm{a}}$ & $0.08774^{\mathrm{a}}$ & $0.4042^{\mathrm{a}}$ & $0.9^{\mathrm{b}}$ \\
Vossa & $0.07566^{\mathrm{a}}$ & $0.06897^{\mathrm{a}}$ & $0.06389^{\mathrm{a}}$ & $0.7078^{\mathrm{a}}$ & $0.84^{\mathrm{b}}$ \\
Ladji & $0.1737^{\mathrm{b}}$ & $0.07146^{\mathrm{a}}$ & $0.0774^{\mathrm{a}}$ & $1.194^{\mathrm{b}}$ & $0.92^{\mathrm{b}}$ \\
Bame & $0.1106^{\mathrm{a}}$ & $0.0588^{\mathrm{a}}$ & $0.06223^{\mathrm{a}}$ & $0.2901^{\mathrm{a}}$ & $0.78^{\mathrm{b}}$ \\
Malanville & $0.06549^{\mathrm{a}}$ & $0.04949^{\mathrm{a}}$ & $0.04871^{\mathrm{a}}$ & $0.1723^{\mathrm{a}}$ & $0.90^{\mathrm{b}}$ \\
Parakou & $0.1536^{\mathrm{b}}$ & $0.08124^{\mathrm{a}}$ & $0.08871^{\mathrm{a}}$ & $0.4698^{\mathrm{a}}$ & $0.74^{\mathrm{b}}$ \\
Tanguieta & $0.2267^{\mathrm{b}}$ & $0.1585^{\mathrm{b}}$ & $0.1442^{\mathrm{b}}$ & $0.182^{\mathrm{b}}$ & $0.85^{\mathrm{b}}$ \\
\hline
\end{tabular}

$a, b$ Values with the same superscript do not differ significantly at $a=0.05$

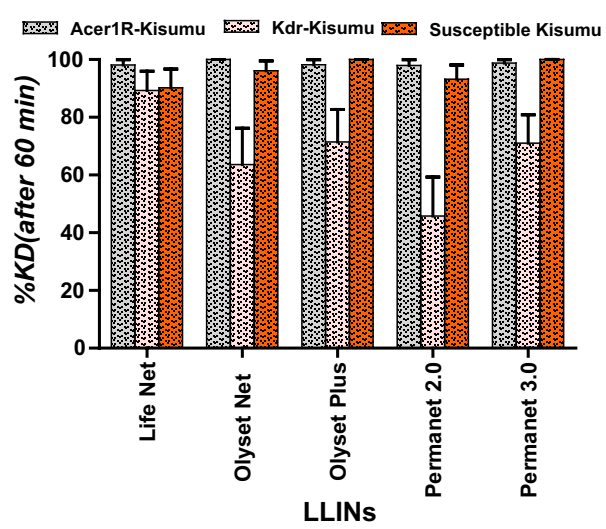

Fig. 2 Mosquito knock-down at 60 min post-exposure to LLINs

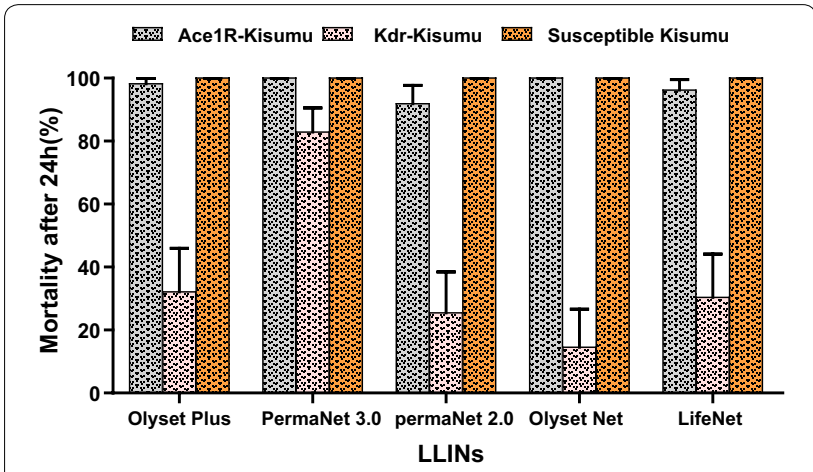

Fig. 3 Mosquito mortalities $24 \mathrm{~h}$ post-exposure to LLINs

3 show the percentage of local strain mosquitoes knocked down after $60 \mathrm{~min}$ for LifeNet, Olyset Net, Olyset Plus, PermaNet 2.0, and PermaNet 3.0.
Knock-down (KD) and mortality induced by the LLINs on mono-resistance mosquito strains

Only PermaNet 3.0, Olyset Plus and LifeNet LLINs showed a knock-down effect greater than 50\% at Agblangandan, Vossa, Zangnanado and Malanville (areas of low resistance) (Table 2). These knock-down values varied between 51 and 95\%. At Abomey, only PermaNet 3.0 and Olyset Plus LLINs showed a knock-down effect greater than $50 \%$.

PermaNet 3.0 was the only LLIN that showed significantly higher mortality of greater than $50 \%$ in all localities where mosquitoes carried only the $k d r$ gene. The average mortality for other types of LLINs tested in these areas varied from 5 to $47 \%$ (Table 2). These mortality rates varied from 0 to $14 \%$ for Olyset, 7 to $27 \%$ for LifeNet, from 9 to $22 \%$ for Olyset Plus, from 24 to $47 \%$ for PermaNet 2.0 and from 40 to $86 \%$ for PermaNet 3.0.

\section{Inhibition of mortality in mono-resistant An. gambiae s.l.} strains

The observed inhibition of mortality induced by $k d r$ resistance of local mosquito strains on LLIN effectiveness was $100-86 \%$ for Olyset, $92-73 \%$ for LifeNet, $53-76 \%$ for PermaNet 2.0, 78-91\% for Olyset Plus and $14-60 \%$ for PermaNet 3.0. These inhibition rates are similar to those observed with the kdr-Kisumu strain ( $p>0.05)$.

\section{Knock-down (KD) and mortality induced by the LLINs} on multi-resistant mosquito strains (carrying $k d r$ and biochemical resistance mutations)

In areas with multi-resistance, the knock-down effects observed were also low (Table 3).

At Akron, the percentage of mosquitoes knocked down after 60 min was 31.48\% [19.52-45.55] and 74.55\% [60.99-85.33] for Olyset Net and Olyset Plus, 
Table 2 Distribution of the knock-down rate observed in localities where there was only one resistance mechanism (kdr)

\begin{tabular}{|c|c|c|c|c|c|}
\hline Strains & LLINs & $\mathrm{N}$ mosquito tested & $\mathrm{KD}$ after $60 \mathrm{~min}$ & $95 \% \mathrm{Cl}$ & Mortality after $24 \mathrm{~h}(\%)$ \\
\hline \multirow[t]{5}{*}{ Malanville } & LifeNet & 55 & 72.27 & [59.03-83.86] & 27.27 \\
\hline & Olyset Net & 53 & 30.19 & [18.34-44.34] & 05.56 \\
\hline & Olyset Plus & 51 & 54.9 & {$[40.34-68.87]$} & 21.56 \\
\hline & PermaNet 2.0 & 59 & 28.81 & {$[17.76-42.08]$} & 47.46 \\
\hline & PermaNet 3.0 & 84 & 95.24 & {$[88.25-98.69]$} & 61.90 \\
\hline \multirow[t]{5}{*}{ Abomey-Calavi } & LifeNet & 53 & 9.43 & {$[3.13-20.66]$} & 7.54 \\
\hline & Olyset Net & 54 & 11.11 & {$[4.18-22.63]$} & 5.56 \\
\hline & Olyset Plus & 55 & 29.09 & [17.62-49.90] & 20 \\
\hline & PermaNet 2.0 & 52 & 70.49 & {$[57.43-81.84]$} & 26.92 \\
\hline & PermaNet 3.0 & 72 & 81.94 & [71.1-90.02] & 86.11 \\
\hline \multirow[t]{5}{*}{ Zagnanado (Bamè) } & LifeNet & 58 & 68.97 & {$[55.45-80.46]$} & 10.34 \\
\hline & Olyset Net & 54 & 23.08 & {$[12.53-36.84]$} & 00 \\
\hline & Olyset Plus & 55 & 33.96 & {$[21.51-46.27]$} & 09.43 \\
\hline & PermaNet 2.0 & 53 & 52.83 & {$[38.63-66.7]$} & 03.77 \\
\hline & PermaNet 3.0 & 75 & 63.93 & [57.61-79.47] & 62.67 \\
\hline \multirow[t]{5}{*}{ Vossa } & LifeNet & 54 & 62.96 & [48.74-75.71] & 20.37 \\
\hline & Olyset Net & 57 & 21.05 & [11.37-33.89] & 14.03 \\
\hline & Olyset Plus & 53 & 41.51 & [28.13-55.87] & 15.05 \\
\hline & PermaNet 2.0 & 51 & 52.94 & [38.45-67.07] & 23.52 \\
\hline & PermaNet 3.0 & 73 & 79.45 & [68.38-88.02] & 39.75 \\
\hline
\end{tabular}

$N$ number, $K D$ knock-down, min minutes, $C l$ confidence interval, $h$ hours

respectively; $70.49 \%[57.43-81.84]$ and $81.71 \%[71.63-$ 89.38] for PermaNet 2.0 and PermaNet 3.0, respectively, and $30.77 \%$ [18.71-45.1] for LifeNet. At Houéyiho, the knock-down effect was 23.08\% [12.53-36.84] and 49.15\% [35.89-62.5] for Olyset Net and Olyset Plus, respectively; 46.3\% [32.62-60.39] and 73.5\% [61.46-83.97] for PermaNet 2.0 and PermaNet 3.0, respectively, and $61.11 \%$ [46.87-74.08] for LifeNet. It was generally observed that knock-down was significantly higher with Olyset Plus than with Olyset on multi-resistant Akron and Houéyiho strains $(\mathrm{p}<0.05)$. The same observation was made with PermaNet 3.0, whose knock-down was significantly higher than that observed with PermaNet 2.0.

The same observations were made at Ladji, Parakou and Tanguiéta, where the KD induced by Olyset Plus was higher than that of Olyset. Similarly, PermaNet 3.0 (98\%) was more effective than PermaNet 2.0 (39\%) (Table 3). However, at Tanguieta, only three LLINs were tested. The three types of mosquitoes tested showed a KD effect $\geq 75 \%$. Overall, in areas where there was high activity of oxidase enzymes associated with the $k d r$ gene, only three LLINs (LifeNet, Olyset Plus, and PermaNet 3.0) showed a KD effect that was generally high. However, the mortality observed in these populations was generally low (Table 3). Only the PermaNet 3.0 LLIN induced significantly higher mortality $(\mathrm{p}<0.001)$ that was generally greater than $75 \%$ (Table 3 ).

\section{Inhibition of mortality in multi-resistant strains}

The inhibition of the mortality induced by LLINs observed with strains carrying several resistance mechanisms (compared to the susceptible strain Kisumu) ranged from 60 to $96 \%$ for Olyset, 53 to $90.2 \%$ for LifeNet, 45 to $86 \%$ for PermaNet $2.0,59$ to $76 \%$ for Olyset Plus and 11 to $55 \%$ for Permanet 3.0. These inhibition rates are similar to those observed with the kdr-Kisumu strains $(\mathrm{p}>0.05)$.

Knock-down time of LLINs on local An. gambiae s.l. strains The average time estimated for knock-down of $50 \%$ of resistant local An. gambiae s.l. populations was significantly shorter with PermaNet 3.0 (12 min) ( $<<0.001)$, followed by Olyset Plus and LifeNet (33 min). However, the time required for $95 \%$ of mosquitoes to be knocked down was high for all LLINs. Generally, there was a slower effect with LLINs treated with permethrin (Table 4).

\section{Discussion}

This study is one of the first conducted in Benin to compare the response of local malaria vectors in Benin to several LLINs recommended by the WHO. It helps to observe the variation in mortality of vectors submitted to different types of LLINs. This mortality was generally low, especially with LLINs only treated with pyrethroids. 
Table 3 Distribution of the knock-down rate observed in localities where there were several resistance mechanisms (kdr + metabolic resistance)

\begin{tabular}{|c|c|c|c|c|c|}
\hline Strains & LLINs & $\mathrm{N}$ mosquito tested & $\mathrm{KD}$ after $60 \mathrm{~min}$ & $95 \% \mathrm{Cl}$ & Mortality (\%) \\
\hline \multirow[t]{5}{*}{ Agblangandan } & LifeNet & 53 & 50.94 & [36.83-64.96] & 15.09 \\
\hline & Olyset Net & 54 & 20.75 & [10.84-34.11] & 07.4 \\
\hline & Olyset Plus & 55 & 50.91 & [37.07-64.65] & 34.72 \\
\hline & PermaNet 2.0 & 47 & 36.17 & [22.67-51.58] & 17.02 \\
\hline & PermaNet 3.0 & 66 & 60.61 & [47.80-72.42] & 65.15 \\
\hline \multirow[t]{5}{*}{ Ladji } & LifeNet & 57 & 85.96 & [74.2-93.74] & 47.36 \\
\hline & Olyset Net & 57 & 50.88 & [37.28-64.37] & 40.35 \\
\hline & Olyset Plus & 56 & 42.86 & [29.71-56.78] & 41.07 \\
\hline & PermaNet 2.0 & 50 & 66 & [51.23-78.79] & 14 \\
\hline & PermaNet 3.0 & 69 & 88.41 & [78.42-94.86] & 44.93 \\
\hline \multirow[t]{5}{*}{ Akron } & LifeNet & 52 & 30.77 & [18.71-45.1] & 15.38 \\
\hline & Olyset Net & 54 & 31.48 & [19.52-45.55] & 5.56 \\
\hline & Olyset Plus & 55 & 74.55 & [60.99-85.33] & 25.45 \\
\hline & PermaNet 2.0 & 61 & 70.49 & [57.43-81.84] & 54.09 \\
\hline & PermaNet 3.0 & 82 & 81.71 & [71.63-89.38] & 89.02 \\
\hline \multirow[t]{5}{*}{ Parakou } & LifeNet & 51 & 43.14 & [29.34-57.75] & 09.80 \\
\hline & Olyset Net & 52 & 26.92 & {$\left[\begin{array}{ll}15.56-4 & 1.02]\end{array}\right.$} & 07.69 \\
\hline & Olyset Plus & 50 & 66 & [51.23-78.79] & 28 \\
\hline & Permanet 2.0 & 56 & 39.29 & [26.49-53.25] & 37.50 \\
\hline & Permanet 3.0 & 88 & 98.86 & [93.83-99.97] & 82.95 \\
\hline \multirow[t]{5}{*}{ Houeyiho } & LifeNet & 54 & 61.11 & [46.87-74.08] & 14.81 \\
\hline & Olyset Net & 52 & 23.08 & [12.53-36.84] & 3.84 \\
\hline & Olyset Plus & 59 & 49.15 & [35.89-62.5] & 23.72 \\
\hline & Permanet 2.0 & 54 & 46.3 & [32.62-60.39] & 22.22 \\
\hline & Permanet 3.0 & 65 & 73.85 & [61.46-83.97] & 61.54 \\
\hline \multirow[t]{5}{*}{ Tanguieta } & LifeNet & - & - & - & - \\
\hline & Olyset Net & - & - & - & - \\
\hline & Olyset Plus & 51 & 74.51 & [60.36-85.67] & 56.86 \\
\hline & PermaNet 2.0 & 62 & 75.81 & [63.25-85.78] & 32.26 \\
\hline & PermaNet 3.0 & 86 & 100 & [88.78-100] & 78.82 \\
\hline
\end{tabular}

$N$ number, KD knock-down, min minutes, $C l$ confidence interval, $h$ hours

Table 4 Probable time for 50 and $95 \%$ knock-down of Anopheles gambiae s.I. per LLIN

\begin{tabular}{|c|c|c|c|c|}
\hline LLINs & $\begin{array}{l}50 \% \text { KDT } \\
\text { (min) }\end{array}$ & $95 \% \mathrm{Cl}$ & $\begin{array}{l}95 \% \text { KDT } \\
(\mathrm{min})\end{array}$ & $95 \% \mathrm{Cl}$ \\
\hline LifeNet & 33.12 & {$[32.5-33.91]$} & 425.13 & $\begin{array}{l}{[385.6-} \\
468.69]\end{array}$ \\
\hline Olyset Net & 98.74 & $\begin{array}{l}{[90.4-} \\
\quad 107.85]\end{array}$ & $10,257.58$ & $\begin{array}{c}{[7090.39-} \\
14,839.5]\end{array}$ \\
\hline Olyset Plus & 33.44 & $\begin{array}{l}{[32.56-} \\
34.34]\end{array}$ & 674.68 & $\begin{array}{r}{[595.91-} \\
763.86]\end{array}$ \\
\hline $\begin{array}{l}\text { PermaNet } \\
2.0\end{array}$ & 42.3 & $\begin{array}{r}{[41.26-} \\
43.37]\end{array}$ & 468.28 & $\begin{array}{r}{[424.57-} \\
516.49]\end{array}$ \\
\hline PermaNet3.0 & 12.61 & $\begin{array}{c}{[12.30-} \\
12.93]\end{array}$ & 137.99 & $\begin{array}{l}{[131.6-} \\
144.69]\end{array}$ \\
\hline
\end{tabular}

\%KDT knock down time, IC 95\% confidence interval at 95\%, min minutes, CI confidence interval
Cone tests showed that LLINs treated with piperonyl butoxide and pyrethroids (especially PermaNet 3.0) have optimum efficacy on all strains of An. gambiae s.l. (mono and multi-resistant).

Several studies have shown a decrease in the bio-efficacy of LLINs against local pyrethroid-resistant vectors $[34,35]$. The effectiveness of LLINs treated only with deltamethrin (PermaNet 2.0 and LifeNet) was found to be significantly lower compared to that of nets treated with deltamethrin and PBO. The same observation was made with the LLINs treated with permethrin only (Olyset Net) and those treated with permethrin and PBO. However, the effectiveness of LLINs treated with permethrin was generally lower than that of LLINs treated with deltamethrin, with lower mortality and a very slow knock-down 
time (KDT 50 and 95\%) compared to other LLINs. In a recent study conducted in Benin [36], Olyset Plus, treated with permethrin $+\mathrm{PBO}$, demonstrated a higher efficacy than Olyset Net against wild multi-resistant An. gambiae s.l. in experimental huts, as observed in WHO cone tests used in the present study. In south-western Ethiopia [35] and in Uganda [34], a reduced efficacy of mono-treated LLINs was also observed against wild resistant An. gambiae s.l. in comparison with Permanet 3.0 treated with deltamethrin + PBO. The results are similar to those observed in this study. However, these studies did not include Olyset Plus, the second type of new-generation LLINs treated with permethrin $+\mathrm{PBO}$.

The reduced efficacy of LLINs treated with permethrin would be related to the strong resistance of the local vectors to permethrin due to the resistance selection pressures generated by the use of the same class of insecticide for malaria vector control in public health and for pest control in agriculture [16, 17, 23, 37, 38].

The comparison of LLIN bio-efficacy performed in this study provides the necessary information for the selection of appropriate LLINs for mass distribution. The optimal and constant efficacy of PermaNet 3.0 LLINs on all vector populations shows that this combination of deltamethrin and PBO on LLINs is a most successful strategy against pyrethroid resistance in Benin. Variations in the mortality of vectors also showed that certain types of LLINs are more appropriate than others for distribution in specific regions. This is related to the fact that the effectiveness of an LLIN depends on the characteristics of the mosquito population tested and the chemical structure of the molecule (insecticide) used.

The mosquito populations assessed in the present study were characterized by a high frequency of the $k d r$ gene. This high frequency was probably due to the massive use of pyrethroids in agriculture and public health. In some areas, such as Tanguieta, Parakou, Houeyiho, Akron, and Ladji, farmers and gardeners use huge amounts of insecticides to reduce pests in their crops, which explains the presence and strong expression of several resistance mechanisms in the mosquito populations [39, 40]. Overproduction of resistance enzymes in these areas would be linked to pressure on mosquito larvae from insecticides used by farmers to protect vegetable crops [41-43]. This expression of the $k d r$ resistance gene induced a $17-84 \%$ reduction in LLIN efficacy against laboratory strains. These frequencies are similar to those observed in natural populations of An. gambiae s.l. This observation shows that the $k d r$ gene is the main mechanism involved in the reduction of the effectiveness of LLINs. Although detoxification enzymes contribute to resistance, their impact is successfully inhibited by the presence of $\mathrm{PBO}$ on new-generation LLINs and the remaining part is more likely related to the presence of $k d r$ gene in the mosquito populations. This also suggests that the search for new molecules or combinations of molecules that target the $k d r$ resistance mechanism should be promoted.

The WHO recommends preventive measures against vector resistance to insecticides [44]. The results of this study therefore constitute important evidence that can guide decision making in the selection and distribution of high efficacy LLINs in specific regions of Benin. The use of LLINs that showed high bio-efficacy against the local vector populations should be encouraged to contribute substantively to reducing the transmission of malaria in Benin.

This study also suggests the need to develop a routine for monitoring the bio-efficacy of LLINs against local malaria vectors for the replacement of ineffective LLINs. However, community studies would be needed to evaluate the epidemiological impact of these LLINs to confirm whether or not the low efficacy observed is followed by a loss of the epidemiological impact of these nets.

Although the important results of this study, it had certain limitations. Strong evaluation would have been possible if tunnel tests were conducted on LLINs that did not meet the criteria of $80 \%$ mortality with resistant mosquito strains. In addition, a chemical analysis of the LLINs prior to the start of the study would also have improved the quality of the results. However, all the LLINs demonstrated a good performance with susceptible laboratory stain Kisumu (mortality $>80 \%$ ), as recommended by WHO [45], and the focus of this study was to demonstrate the important role of resistance mechanisms on LLINs efficacy.

\section{Conclusion}

This study showed variable effectiveness of LLINs on $A n$. gambiae s.l. populations from different localities surveyed from north to south in Benin. The new-generation LLINs with pyrethroids and PBO (PermaNet 3.0 and Olyset Plus) showed higher efficacy than conventional LLINs (PermaNet 2.0, LifeNet and Olyset net). However, the strong resistance of local vectors to permethrin suggests that the combination of deltamethrin $+\mathrm{PBO}$ is the most appropriate strategy against local vectors in Benin. Although the addition of $\mathrm{PBO}$ (targeting many biochemical mechanisms of resistance) significantly increased the mortality of mosquitoes, the significantly high role of the $k d r$ resistance gene in the low efficacy of LLINs calls for LLIN technology innovation that specifically targets this mechanism.

\section{Authors' contributions}

MA, VG and MCA designed the study, supervised laboratory work, analyzed data and wrote the manuscript. BY, RA, FA and BA conducted field collections, laboratory tests and contributed in the writing of the manuscript. AH and GGP helped in the study design and revising the manuscript. All authors read and approved the final manuscript. 


\author{
Author details \\ ${ }^{1}$ Centre de Recherche Entomologique de Cotonou (CREC), Cotonou, \\ Benin. ${ }^{2}$ Université d'Abomey-Calavi, Abomey-Calavi, Benin. ${ }^{3}$ Medical Care \\ and Development International, Washington, USA.
}

\section{Acknowledgements}

We thank CREC personnel for their technical assistance and collaboration.

\section{Competing interests}

The authors declare that they have no competing interests.

\section{Availability of data and materials}

Data collected during this study are included in the published article and its additional files.

\section{Funding}

This work is supported by Faculty of Letters, Arts and Human Sciences of the University of Abomey-Calavi.

Received: 5 December 2016 Accepted: 7 February 2017

Published online: 15 February 2017

\section{References}

1. WHO. World malaria report 2015. Geneva: World Health Organization; 2015. http://www.who.int/malaria/publications/world-malariareport-2015/report/en/. Accessed 15 Aug 2016.

2. Gimnig JE, Lindblade KA, Mount DL, Atieli FK, Crawford S, Wolkon A, et al. Laboratory wash resistance of long-lasting insecticidal nets. Trop Med Int Health. 2005:10:1022-9.

3. WHO. The Abuja declaration and the plan of action. An extract from the African Summit on Roll Back Malaria. Geneva: World Health Organization: 2003; p. 1-11. http://www.who.int/malaria/publications/atoz/whocdsrbm200346/en/. Accessed 15 Aug 2016.

4. Carnevale P, Robert V, Boudin C, Halna JM, Pazart L, Gazin P, et al. Control of malaria using mosquito nets impregnated with pyrethroids in Burkina Faso. Bull Soc Path Exot Filiales. 1988;81:832-46 (in French)

5. Desfontaine M, Gelas H, Cabon H, Goghomou A, Kouka Bemba D, Carnevale P. Evaluation des pratiques et des couts de lutte antivectorielle à l'échelon familial en Afrique Centrale. II. Ville de Douala (Cameroun), juillet 1988. Ann Soc Belge Méd Trop. 1990;70:137-44.

6. Alonso PL, Lindsay SW, Armstrong JRM, de Francisco A, Shenton FC, Greenwood BM, et al. The effect of insecticide-treated bed nets on mortality of Gambian children. Lancet. 1991;337:1499-502.

7. D'Alessandro U, Olaleye BO, McGuire W, Thomson MC, Langerock P, Bennett $S$, et al. A comparison of the efficacy of insecticide-treated and untreated bed nets in preventing malaria in Gambian children. Trans $R$ Soc Trop Med Hyg. 1995;89:596-8.

8. Aikins MK, Fox-Rushby J, D'Alessandro U, Langerock P, Cham K, New L, et al. The Gambian National Impregnated Bednet Programme: costs, consequences and net cost-effectiveness. Soc Sci Med. 1998;46:181-91.

9. Snow RW, Rowan KM, Lindsay SW, Greenwood BM. A trial of bed nets (mosquito nets) as a malaria control strategy in a rural area of The Gambia, West Africa. Trans R Soc Trop Med Hyg. 1988;82:212-5.

10. Karch S, Garin B, Asidi N, Manzambi Z, Salaun JJ, Mouchet J. Moustiquaires impregnées contre le paludisme au Zaire. Ann Soc Belge Méd Trop. 1993;73:37-53.

11. Nevill CG, Some ES, Mung'ala VO, Mutemi W, New L, Marsh K, et al. Insecticide-treated bednets reduce mortality and severe morbidity from malaria among children on the Kenyan coast. Trop Med Int Health. 1996;1:139-46.

12. Binka FN, Kubaje A, Adjuik M, Williams LA, Lengeler C, Maude GH, et al. Impact of permethrin impregnated bednets on child mortality in Kassena-Nankana district, Ghana: a randomized controlled trial. Trop Med Int Health. 1996:1:147-54.

13. Akogbeto PM, Nahum A. Impact of deltamethrin impregnated mosquito nets on the transmission of malaria in the coastal lagoon area, Benin. Bull Soc Path Exot. 1996:89:291-8 (in French).
14. Mathanga DP, Campbell CH, Taylor TE, Barlow R, Wilson ML. Reduction of childhood malaria by social marketing of insecticide-treated nets: a case-control study of effectiveness in Malawi. Am J Trop Med Hyg. 2005;73:622-5

15. Chandre F, Darriet F, Manguin S, Brengues C, Carnevale P, Guillet P. Pyrethroid cross resistance spectrum among populations of Anopheles gambiae s.s. from Côte d'Ivoire. J Am Mosq Control Assoc. 1999:15:53-9.

16. Akogbeto $M$, Yakoubou S. Resistance of malaria vectors to pyrethrins used for impregnating mosquito nets in Benin, West Africa. Bull Soc Pathol Exot. 1999:92:123-30 (in French)

17. Akogbeto MC, Djouaka R, Noukpo H. Use of agricultural insecticides in Benin. Bull Soc Pathol Exot. 2005;98:400-5 (in French)

18. Corbel V, N'Guessan R, Brengues C, Chandre F, Djogbenou L, Martin T, et al. Multiple insecticide resistance mechanisms in Anopheles gambiae and Culex quinquefasciatus from Benin, West Africa. Acta Trop. 2007:101:207-16.

19. N'Guessan R, Corbel V, Bonnet J, Yates A, Asidi A, Boko P, et al. Evaluation of indoxacarb, an oxadiazine insecticide for the control of pyrethroidresistant Anopheles gambiae (Diptera: Culicidae). J Med Entomol. 2007:44:270-6.

20. Djènontin A, Chabi J, Baldet T, Irish S, Pennetier C, Hougard JM, et al. Managing insecticide resistance in malaria vectors by combining carbamatetreated plastic wall sheeting and pyrethroid-treated bed nets. Malar J. 2009;8:233.

21. Yadouleton AW, Padonou G, Asidi A, Moiroux N, Bio-Banganna S, Corbe $V$, et al. Insecticide resistance status in Anopheles gambiae in southern Benin. Malar J. 2010:9:83.

22. Djogbénou L, Pasteur N, Akogbéto M, Weill M, Chandre F. Insecticide resistance in the Anopheles gambiae complex in Benin: a nationwide survey. Med Vet Entomol. 2011;25:256-67.

23. Gnanguenon V, Agossa FR, Badirou K, Govoetchan R, Anagonou R, OkeAgbo F, et al. Malaria vectors resistance to insecticides in Benin: current trends and mechanisms involved. Parasit Vectors. 2015:8:223.

24. Henry MC, Assi SB, Rogier C, Yovo DJ, Chandre F, Guillet P, et al. Protective efficacy of lambda-cyhalothrin treated nets in Anopheles gambiae pyrethroid resistance areas of Cote d'Ivoire. Am J Trop Med Hyg. 2005;73:859-64.

25. Curtis CF, Jana-Kara B, Maxwell CA. Insecticide treated nets: impact on vector populations and relevance of initial intensity of transmission and pyrethroid resistance. J Vector Borne Dis. 2003:40:1-8.

26. Asidi A, N'Guessan R, Akogbeto M, Curtis C, Rowland M. Loss of household protection from use of insecticide-treated nets against pyrethroidresistant mosquitoes, Benin. Emerg Infect Dis. 2012;18:1101-6.

27. Aïkpon $R$, Sèzonlin $M$, Ossè $R$, Akogbéto $M$. Evidence of multiple mechanisms providing carbamate and organophosphate resistance in field An gambiae population from Atacora in Benin. Parasit Vectors. 2014;7:568

28. Corbel V, Hougard J-M, N'Guessan R, Chandre F. Evidence for selection of insecticide resistance due to insensitive acetylcholinesterase by carbamate-treated nets in Anopheles gambiae s.s. (Diptera: Culicidae) from Côte d'Ivoire. J Med Entomol. 2003;40:985-8.

29. Kweka EJ, Lyaruu LJ, Mahande AM. Efficacy of PermaNet ${ }^{\circledR} 3.0$ and PermaNet ${ }^{\circledR} 2.0$ nets against laboratory-reared and wild Anopheles gambiae sensu lato populations in northern Tanzania. Infect Dis Poverty. 2017:6:11.

30. Brogdon WG, McAllister JC, Vulule JM. Association of heme peroxidase activity measured in single-mosquitoes identifies individuals expressing an elevated oxidase for insecticide resistance. J Am Mosq Control Assoc. 1997;13:233-7

31. Martinez-Torres D, Chandre F, Williamson MS, Darriet F, Bergé JB, Devonshire AL, et al. Molecular characterization of pyrethroid knockdown resistance $(\mathrm{kdr})$ in the major malaria vector Anopheles gambiae s.s. Insect Mol Biol. 1998;7:179-84

32. Hemingway J, Hawkes N, Prapanthadara L, Jayawardenal KGl, Ranson H. The role of gene splicing, gene amplification and regulation in mosquito insecticide resistance. Philos Trans R Soc Lond B Biol Sci. 1998;353:1695-9.

33. Finney D. Review of probit analysis: a statistical treatment of the sigmoid response curve. J R Stat Soc. 1947:110:263-6.

34. Okia M, Ndyomugyenyi R, Kirunda J, Byaruhanga A, Adibaku S, Lwamafa DK, et al. Bioefficacy of long-lasting insecticidal nets against pyrethroidresistant populations of Anopheles gambiae s.s. from different malaria transmission zones in Uganda. Parasit Vectors. 2013:6:130. 
35. Yewhalaw D, Asale A, Tushune K, Getachew Y, Duchateau L, Speybroeck N. Bio-efficacy of selected long-lasting insecticidal nets against pyrethroid resistant Anopheles arabiensis from South-Western Ethiopia. Parasit Vectors. 2012;5:159.

36. Pennetier C, Bouraima A, Chandre F, Piameu M, Etang J, Rossignol M, et al. Efficacy of Olyset ${ }^{\circledR}$ Plus, a new long-lasting insecticidal net incorporating permethrin and piperonil-butoxide against multi-resistant malaria vectors. PLoS ONE. 2013;8:e75134.

37. Ranson H, Abdallah H, Badolo A, Guelbeogo WM, Kerah-Hinzoumbé C, Yangalbé-Kalnoné $\mathrm{E}$, et al. Insecticide resistance in Anopheles gambiae: data from the first year of a multi-country study highlight the extent of the problem. Malar J. 2009;8:299.

38. Chouaibou MS, Chabi J, Bingham GV, Knox TB, N'Dri L, Kesse NB, et al. Increase in susceptibility to insecticides with aging of wild Anopheles gambiae mosquitoes from Côte d'Ivoire. BMC Infect Dis. 2012;12:214.

39. Akogbéto MC, Djouaka RF, Kindé-Gazard DA. Screening of pesticide residues in soil and water samples from agricultural settings. Malar J. 2006;5:22.

40. Yadouleton A, Asidi A, Djouaka R, Braïma J, Agossou C, Akogbeto M. Development of vegetable farming: a cause of the emergence of insecticide resistance in populations of Anopheles gambiae in urban areas of Benin. Malar J. 2009;8:103.

41. Diabate A, Baldet T, Chandre F, Akogbeto M, Guiguemde TR, Darriet F, et al. The role of agricultural use of insecticides in resistance to pyrethroids in Anopheles gambiae s.l. in Burkina Faso. Am J Trop Med Hyg. 2002;67:617-22.

42. Djouaka R, Irving H, Tukur Z, Wondji CS. Exploring mechanisms of multiple insecticide resistance in a population of the malaria vector Anopheles funestus in Benin. PLoS ONE. 2011;6:e27760.

43. Aikkpon R, Agossa F, Ossè R, Oussou O, Aïzoun N, Oké-Agbo F, et al. Bendiocarb resistance in Anopheles gambiae s.l. populations from Atacora department in Benin, West Africa: a threat for malaria vector control. Parasit Vectors. 2013;6:192.

44. WHO. Test procedures for insecticide resistance monitoring in malaria vector mosquitoes. Geneva: World Health Organization; 2013.

45. WHO. Guidelines for laboratory and field-testing of long-lasting insecticidal nets. Geneva: World Health Organization; 2013. p. 1-102.

\section{Submit your next manuscript to BioMed Central and we will help you at every step:}

- We accept pre-submission inquiries

- Our selector tool helps you to find the most relevant journal

- We provide round the clock customer support

- Convenient online submission

- Thorough peer review

- Inclusion in PubMed and all major indexing services

- Maximum visibility for your research

Submit your manuscript at www.biomedcentral.com/submit 